ఠ

\title{
Endothelial function, blood pressure control, and risk modification: impact of irbesartan alone or in combination
}

This article was published in the following Dove Press journal:

integrated Blood Pressure Control

18 May 2010

Number of times this article has been viewed

\author{
Giuseppe Derosa \\ Sibilla AT Salvadeo \\ Department of Internal Medicine and \\ Therapeutics, University of Pavia, \\ Pavia, Italy
}

\begin{abstract}
Irbesartan, an angiotensin II type 1 receptor antagonist, is approved as monotherapy, or in combination with other drugs, for the treatment of hypertension in many countries worldwide. Data in the literature suggest that irbesartan is effective for reducing blood pressure over a 24-hour period with once-daily administration, and slows the progression of renal disease in patients with hypertension and type 2 diabetes. Furthermore, irbesartan shows a good safety and tolerability profile, compared with angiotensin II inhibitors and other angiotensin II type 1 receptor antagonists. Thus, irbesartan appears to be a useful treatment option for patients with hypertension, including those with type 2 diabetes and nephropathy. Irbesartan has an inhibitory effect on the pressor response to angiotensin II and improves arterial stiffness, vascular endothelial dysfunction, and inflammation in hypertensive patients. There has been considerable interest recently in the renoprotective effect of irbesartan, which appears to be independent of reductions in blood pressure. In particular, mounting data suggests that irbesartan improves endothelial function, oxidative stress, and inflammation in the kidneys. Recent studies have highlighted a possible role for irbesartan in improving coronary artery inflammation and vascular dysfunction. In this review we summarize and comment on the most important data available with regard to antihypertensive effect, endothelial function improvement, and cardiovascular risk reduction with irbesartan.
\end{abstract}

Keywords: blood pressure, hypertension, endothelial function, irbesartan, antihypertensive drugs, combination therapy

\section{Introduction}

\section{Hypertension and cardiovascular risk}

Several studies have shown that elevated blood pressure (BP) is a major risk factor for cardiovascular morbidity and mortality. This relationship is strong and continuous in a range of patient populations and age groups. ${ }^{1-5}$ Most of the major guidelines for the treatment of hypertension recommend that individuals with a $\mathrm{BP} \geq 140 / 90 \mathrm{mmHg}$ should be regarded as hypertensive, and treated in order to keep BP below this threshold. Systolic BP and diastolic BP (SBP and DBP, respectively) targets generally must be lower in patients at high cardiovascular risk and in those with diabetes or renal disease. ${ }^{6,7}$

Nearly 40 years ago, data from the Framingham Heart Study showed that SBP was more closely associated with the risk of cardiovascular disease than DBP. Although DBP was shown to be a more useful predictor of cardiovascular risk in hypertensive patients younger than 45 years, for the majority of hypertensive patients, the ability of SBP to predict ischemic cardiovascular disease was not improved by addition of
Correspondence: Giuseppe Derosa Department of Internal Medicine and Therapeutics, University of Pavia, Ple C Golgi, 2-27I00 Pavia, Italy Tel +390382526217 Fax +390382526259 Email giuseppe.derosa@unipv.it 
DBP data. The superior predictive ability of SBP was more recently confirmed by the Prospective Studies Collaboration, a meta-analysis of 61 prospective observational studies that recorded BP and cause-specific mortality. ${ }^{5}$ In this study, Lewington et al found that SBP at baseline was more informative than DBP as a predictor of stroke and mortality from ischemic heart disease. Moreover the study concluded that, in middle-aged individuals, prolonged reductions in usual SBP of only $2 \mathrm{mmHg}$ would lead to substantial reductions in the incidence of death secondary to stroke (a 7\% reduction) and other vascular causes $(10 \%)$. $^{5,11}$

These data are supported by those of Stamler et al who found that SBP had a stronger association with cardiovascular risk than DBP in middle-aged and elderly individuals. At every level of DBP in this population, a higher SBP value was associated with greater cardiovascular risk and lower life expectancy. ${ }^{12}$

Recently, Benetos et al aimed to determine whether the high cardiovascular mortality rate in treated hypertensive patients was due to hypertension or to the presence of associated risk factors and/or diseases. Using cardiovascular mortality data from treated hypertensive patients $(\mathrm{n}=8893)$ and from untreated age- and gender-matched normotensive and hypertensive controls $(n=25,880)$ enrolled in the Investigations Préventives et Cliniques cohort, Benetos et al observed that the two-fold increase in cardiovascular and coronary mortality found in treated hypertensive patients persisted after adjustment for cardiovascular risk factors. Adjustment for SBP was necessary to make the mortality rates similar in the two populations. Subsequent inclusion of DBP in the model did not modify the between-group risk ratio. These results suggest that the increased cardiovascular mortality in treated hypertensive patients is mainly due to uncontrolled SBP levels. ${ }^{13}$

Moreover, the incidence of most adverse cardiovascular events appears to follow a circadian pattern, reaching a peak in the morning shortly after waking and arising. The activity of many physiologic parameters fluctuates in a cyclical manner over 24 hours. It has been suggested that, during the post-awakening hours, the phases of hemodynamic, hematologic, and humoral cycles synchronize, thus creating an environment that predisposes to atherosclerotic plaque rupture and thrombosis in susceptible individuals. BP and heart rate follow a clear circadian rhythm. The increased SBP and DBP in the morning may act as a trigger for cardiovascular events, including myocardial infarction and stroke. The clinical implication of these observations is that antihypertensive therapy should provide BP control over the entire interval between doses. ${ }^{14}$
There is strong evidence that sustain the high variability of BP over 24 hours. ${ }^{15}$ Furthermore, data from cross-sectional studies ${ }^{16}$ suggest that target organ damage is greater in hypertensive persons with high BP variability. The daytime SBP variability is a strong predictor of early carotid atherosclerosis progression and is useful to define the risk-benefit ratio of therapeutic approaches. A major impact of circadian BP patterns on the development of early carotid atherosclerosis has been demonstrated. ${ }^{17,18}$

\section{Endothelial physiology and dysfunction}

Until a few years ago, the endothelium was considered to be just a cellular barrier between circulating blood and the arterial muscle wall, and was thought to be involved only in the processes of transport, metabolism, and coagulation. However, it has now been demonstrated that most of the pathophysiologic mechanisms that lead to atherosclerosis are located in the endothelium. ${ }^{19}$ The physiologic vascular action of the endothelium is modulated by a series of molecules controlling vasodilation and, to a minor extent, vasoconstriction. ${ }^{20}$ There is mounting evidence to suggest that hypertension is associated with endothelial abnormalities that are not likely to be related to high BP values, and more to hypertension per se. ${ }^{21}$

Accordingly, endothelial dysfunction is not only improved by reduction of BP values, but may also be improved by pharmacologic treatment for hypertension. ${ }^{22}$ The mean feature of endothelium-mediated vasodilatation in hypertensive patients is the reduced availability of nitric oxide (NO). In patients with essential hypertension, activation of endothelial cells induces production of cyclo-oxygenase-dependent factors, such as free radicals, which are responsible for the impaired bioavailability of NO. When cyclo-oxygenase activity is blocked, the bioavailability of $\mathrm{NO}$ is immediately restored. In hypertensive patients, vitamin $\mathrm{C}$ infusion is able to improve acetylcholine (Ach)-induced vasodilatation. ${ }^{23}$

NO bioavailability is usually decreased either by decreased formation or by enhanced removal. The presence of classic cardiovascular risk factors is associated with enhanced generation of radical oxygen species. Superoxide anions $\left(\mathrm{O}^{2-}\right)$ play a pivotal role by reacting with $\mathrm{NO}$, resulting in the formation of peroxynitrite $\left(\mathrm{ONOO}^{-}\right)$, and hence decreasing bioavailability of NO. ${ }^{24}$ Studies with simultaneous measurement of relaxation and release of NO clearly show that endothelial cell signal transduction is altered in hypertension. ${ }^{25}$

Moreover, in studies with healthy human subjects, several agonists (including Ach and bradykinin) have been 
found to induce vasodilation when injected directly into the brachial or coronary circulation. ${ }^{26-28}$ This vasodilation appears mainly regulated by specific NO synthase inhibitors, such as Nv-monomethyl-larginine (L-NMMA). In patients with essential hypertension, the response to endotheliumdependent agonists (mainly Ach or bradykinin) is blunted in different vascular regions when compared with healthy controls. This diminished relation response to Ach or bradykinin is, moreover, resistant to L-NMMA, which suggests the presence of compromised NO availability caused mainly by oxidative stress. ${ }^{29-32}$

Some authors suggest that chronic inflammation may play a significant role in hypertension. A persistent low-grade inflammatory state could be associated with increased levels of cytokine plasma concentration. By impairing the capacity of the endothelium to generate vasodilating factors, particularly NO, elevated cytokines may lead to the development of endothelial dysfunction, chronically impaired vasodilation, and hypertension. ${ }^{33}$

Other studies suggest that endothelial dysfunction may be reversible. Physical exercise, calcium channel blockers (CCBs), angiotensin-converting enzyme inhibitors (ACEIs), and angiotensin receptor antagonists (ARBs) are effective in improving flow-stimulated endothelium-dependent vasodilation in patients with hypertension and diabetes mellitus. ${ }^{34,35}$

The ARB irbesartan shows high efficacy in lowering $\mathrm{BP}$, to a degree comparable with ACEIs and superior to other ARBs, including losartan and valsartan. Moreover, irbesartan has been shown to be effective in both earlyand late-stage diabetic nephropathy. ${ }^{36}$ Irbesartan has furthermore demonstrated considerable cost savings over standard therapy, including beta-blockers, diuretics, and nondihydropyridine CCBs in all stages of kidney disease. Efficacy data from the Irbesartan Diabetic Nephropathy Trial and Reduction of Endpoints with the Angiotensin II Antagonist Losartan Study ${ }^{37}$ has also demonstrated better cost savings with irbesartan than losartan in late-stage renal disease. While both irbesartan and losartan are registered for the treatment of late-stage diabetic nephropathy, irbesartan is also registered for early-stage diabetic nephropathy in the European Union. Some investigators claim there is a genuine value in using irbesartan instead of other ARBs in the treatment of hypertension, ${ }^{38}$ and there is strong evidence of a positive impact from irbesartan in the treatment of hypertensive patients with endothelium-dependent vasodilation. ${ }^{39}$ This effect is partially shared with other ARBs, although the specific activity of irbesartan has been shown in experimental studies. ${ }^{40}$

\section{Pharmacology}

Irbesartan is nearly completely absorbed following oral administration, with an average absolute bioavailability of $60 \%-80 \%$. About $25 \%$ of an administered radioactive dose is excreted in the urine and the remainder is eliminated in feces. ${ }^{41}$ Several determinants of drug disposition, such as gastric acidity, gastric motility, glomerular filtration rate, plasma albumin, and renal and hepatic blood flow are altered in elderly subjects. ${ }^{42}$ It is possible that one or more factors may contribute to the observed significant increases in the $\mathrm{C}_{\max }$ and AUC of irbesartan. Results obtained in renally impaired patients indicated that renal impairment had no clinically important effects on the pharmacokinetics of irbesartan. ${ }^{43}$ Food does not affect the bioavailability of irbesartan, so it can be administered without regard to meals. ${ }^{44}$ Although there is an effect of age on the pharmacokinetics of irbesartan, based on the safety and efficacy profile, no adjustment in irbesartan dosage is necessary with respect to age or gender. ${ }^{45}$

Irbesartan is a selective antagonist for the angiotensin II type $1\left(\mathrm{AT}_{1}\right)$ receptor. The irbesartan concentration needed to reduce specific binding of $125^{\mathrm{I}}$-angiotensin II to rat adrenal cortical microsomes by $50 \%$ is $0.9 \mathrm{nmol} / \mathrm{L}$. Irbesartan has no active metabolites. ${ }^{46}$

\section{Efficacy studies of irbesartan Effects on blood pressure}

The effects of ARBs on hypertension are well known from the literature, and the efficacy of irbesartan in lowering BP is evident both in experimental and clinical studies. ${ }^{47}$ All irbesartan regimens significantly reduced mean 24-hour ambulatory BP values and were well tolerated. Administration of irbesartan $150 \mathrm{mg}$ once a day provides significant reduction of BP for 24 hours, equivalent to that obtained with the same total daily dose divided into two doses. ${ }^{48}$

The antihypertensive effect of irbesartan on both SBP and DBP appears increased when administered in combination with diuretics. In a study by Mugellini et al, reduction of DBP and SBP with irbesartan-hydrochlorothiazide was comparable with that obtained with manidipine-delapril $(-26.4 / 20.2 \mathrm{mmHg}$ and $-27.6 / 21.8 \mathrm{mmHg}$, respectively) and better than that of the respective monotherapies $(-16.3 / 11.3 \mathrm{mmHg}$ with delapril and $-15.2 / 11.7 \mathrm{mmHg}$ with irbesartan) in hypertensive patients with type 2 diabetes mellitus. ${ }^{49}$

Recently, an uncontrolled, multicenter study has confirmed the efficacy of the combination of irbesartan and hydrochlorothiazide. ${ }^{50}$ The aim of this large study was to compare the antihypertensive efficacy of valsartan $80 \mathrm{mg}$ versus 
irbesartan $150 \mathrm{mg}$ when combined with hydrochlorothiazide $12.5 \mathrm{mg}$. Untreated or uncontrolled hypertensive adults $(n=800)$ were enrolled by primary care physicians. After a five-week, open-label, lead-in phase in which all patients received $12.5 \mathrm{mg}$ hydrochlorothiazide once daily, subjects whose BP remained uncontrolled $(n=464)$ were randomized to valsartan-hydrochlorothiazide $(80 / 12.5 \mathrm{mg})$ or irbesartanhydrochlorothiazide (150/12.5 mg). After eight weeks, the irbesartan-hydrochlorothiazide combination produced greater reductions in average SBP and DBP measured by home BP monitoring than did valsartan-hydrochlorothiazide (SBP -13.0 versus $-10.6 \mathrm{mmHg}, P=0.0094$; DBP -9.5 versus $-7.4 \mathrm{mmHg}, P=0.0007$, respectively). Comparable results were obtained between the groups for clinic BP measurements. The overall drug safety was similar between the two treatment groups. ${ }^{51}$

An irbesartan-hydrochlorothiazide fixed-dose combination has been approved for clinical use, and its efficacy and safety has recently been evaluated in a study of 96 hypertensive diabetic patients randomized to 12 months of doubleblind treatment with doxazosin $4 \mathrm{mg} /$ day or irbesartan $300 \mathrm{mg} /$ day. ${ }^{52}$ At the end of the study, SBP and DBP were significantly $(P<0.01)$ reduced from 152 to $140 \mathrm{mmHg}$ and from 97 to $87 \mathrm{mmHg}$, respectively, with doxazosin. SBP and DBP were reduced from 150 to $134 \mathrm{mmHg}$ and from 94 to $83 \mathrm{mmHg}$, respectively, with irbesartan $(P<0.01)$. Irbesartan had significantly better antihypertensive efficacy than doxazosin $(P<0.05) .{ }^{53}$ In patients with increased DBP, irbesartan shows comparable efficacy to that of amlodipine. In a study of non-African-American patients with a seated DBP of 95-100 mmHg, irbesartan $150 \mathrm{mg} /$ day did not show any significant difference in DBP-lowering effect compared with amlodipine $5 \mathrm{mg} /$ day. ${ }^{54}$

In a recent study by Fogari et al, 94 hypertensive patients were randomized to valsartan $160 \mathrm{mg}+$ amlodipine $5 \mathrm{mg}$ or irbesartan $300 \mathrm{mg}$ + hydrochlorothiazide $12.5 \mathrm{mg}$ for 24 weeks after a four-week placebo period. Both combinations significantly reduced clinical seated and lying BP values, with no difference between treatments. BP changes from the lying to standing position were significantly greater in the irbesartan-hydrochlorothiazide group $(-17.2 /-9.1 \mathrm{mmHg})$ than in the valsartan-amlodipine group $(-10.1 /-1.9 \mathrm{mmHg}$, $P<0.05$ for SBP and $P<0.01$ for DBP versus irbesartanhydrochlorothiazide). Both combinations were similarly effective in reducing ambulatory and clinical BP in very elderly hypertensive subjects. ${ }^{55}$

Compared with ACEIs, irbesartan has a similar effect on $\mathrm{BP}$ reduction, with fewer adverse events recorded for irbesartan. In a double-blind, randomized study, an irbesartan-based antihypertensive regimen reduced SBP/ DBP by 40/30 mmHg after 12 weeks in patients with severe hypertension. This reduction was at least equivalent to that of a regimen using enalapril up to $40 \mathrm{mg}$. The irbesartanbased regimen had a better tolerability profile with fewer adverse events (55\% versus 64\%) and significantly less cough (2.5\% versus $13.1 \%, P=0.007) .{ }^{56}$ These results have been confirmed in a larger clinical trial comparing irbesartan and enalapril. Two hundred and thirty-eight patients were randomized to treatment, and the study was completed by 111 patients in the irbesartan group (dose titrated to $300 \mathrm{mg} /$ day in $72.0 \%$ of patients) and 115 patients in the enalapril group (dose titrated to $20 \mathrm{mg} /$ day in $76.5 \%$ of patients). BP reductions were similar in the two groups, both as measured in the clinic (DBP $-12.7 \pm 8.8 \mathrm{mmHg}$ for irbesartan versus $-12.4 \pm 7.4 \mathrm{mmHg}$ for enalapril; SBP $-19.0 \pm 14.1 \mathrm{mmHg}$ versus $-17.5 \pm 14.0 \mathrm{mmHg}$, respectively) and by 24-hour ambulatory BP monitoring (DBP $-9.4 \pm 8.5 \mathrm{mmHg}$ versus $-8.8 \pm 8.5 \mathrm{mmHg}$; $\mathrm{SBP}-14.7 \pm 14.7 \mathrm{mmHg}$ versus $-12.6 \pm 13.1 \mathrm{mmHg}$ ). The overall incidence of adverse events (40.0\% for irbesartan, $51.2 \%$ for enalapril) was not statistically different between the treatment groups, although the incidence of adverse events, probably related to antihypertensive treatment, was significantly higher with enalapril than with irbesartan $(24.6 \%$ versus $9.2 \%$, respectively, $P=0.026)$, and were essentially accounted for by a higher incidence of cough $\left(8.1 \%\right.$ versus $0.9 \%$, respectively). ${ }^{57}$

Compared with other ARBs, irbesartan shows equal or greater efficacy in reducing both SBP and DBP. In a study by Mancia et al, irbesartan was more effective than valsartan in reducing DBP and SBP at trough levels and in providing greater overall 24-hour BP lowering. In another study, after a three-week, single-blind, placebo lead-in period, 426 subjects were randomized to receive either irbesartan $150 \mathrm{mg}$ or valsartan $80 \mathrm{mg}$ for eight weeks. At the end of the study, irbesartan provided significantly greater reductions than valsartan for mean change from baseline in diastolic ambulatory BP at trough $(-6.73$ versus $-4.84 \mathrm{mmHg}$, respectively, $P=0.035)$ and in mean systolic ambulatory BP at trough $(-11.62$ versus $-7.5 \mathrm{mmHg}$, respectively, $P<0.01)$. Similar results were obtained for mean 24-hour diastolic ambulatory BP (-6.38 versus $-4.82 \mathrm{mmHg}$, respectively, $P=0.023$ ) and systolic ambulatory BP $(-10.24$ versus $-7.76 \mathrm{mmHg}, P<0.01)$. Irbesartan also produced significantly greater reductions than valsartan for office-measured seated DBP $(-10.46$ versus $-7.28 \mathrm{mmHg}$, respectively, $P<0.01)$ and SBP $(-16.23$ versus $-9.96 \mathrm{mmHg}$, respectively, $P<0.01)$ and 
for self-measured morning DBP $(-6.28$ versus $-3.75 \mathrm{mmHg}$, respectively, $P<0.01)$ and $\mathrm{SBP}(-10.21$ versus $-6.97 \mathrm{mmHg}$, respectively, $P<0.01) .{ }^{58}$

\section{Effects on vascular endothelium}

Recent findings suggest that $\mathrm{AT}_{1}$ receptor blockade improves superoxide production and NO bioavailability more than do other classes of antihypertensive agents. In a study by Brosnan et al, in vivo irbesartan, amlodipine, and hydrochlorothiazide-hydralazine produced similar reductions in BP values, but irbesartan caused a greater reduction in superoxide and p22phox in carotid arteries. Four-hour in vitro exposure to irbesartan decreased superoxide levels in the aorta and increased NO bioavailability in carotid arteries. Neither 30-minute incubation with irbesartan nor four hours with amlodipine or hydrochlorothiazide-hydralazine altered superoxide levels. Reduced expression of components of nicotinamide adenine dinucleotide phosphate (NADPH) oxidase may contribute to these effects. ${ }^{59}$

Moreover, a protective effect of $\mathrm{AT}_{1}$ receptor blockers on endothelial function during postprandial hypertriglyceridemia has been reported in healthy subjects. ${ }^{60}$ In 2005, Ceriello et al demonstrated, for the first time, that irbesartan, like statins, is able to ameliorate the damage done to endothelial function by postprandial hyperglycemia and hypertriglyceridemia, oxidative stress, and inflammation in diabetic patients. These results appeared not to be linked to the BP-lowering effect and were obtained after short-term treatment. In this study, combination treatment of atorvastatin and irbesartan showed a more powerful effect on vascular damage compared with monotherapy using irbesartan or atorvastatin. ${ }^{61}$

Pharmacodynamic data suggest that irbesartan at a dose of $300 \mathrm{mg}$ provides more effective and persistent $\mathrm{AT}_{1}$ blockade than losartan $100 \mathrm{mg}$. In a short-term (eight week) study by Kassler-Taub et al, after a placebo lead-in, 567 patients were randomized to once-daily therapy with placebo, losartan $100 \mathrm{mg}$, irbesartan $150 \mathrm{mg}$, or irbesartan $300 \mathrm{mg}$. At the end of the study, reductions from baseline in seated DBP and seated SBP with irbesartan $300 \mathrm{mg}$ were greater than those obtained with losartan $100 \mathrm{mg}$ by -3.0 and $-5.1 \mathrm{mmHg}$, respectively ( $P<0.01$ for both comparisons). Larger reductions were also demonstrated at weeks 1 and $4(P<0.01$ and $P=0.017$, respectively, for DBP and SBP) of the study, and the antihypertensive effects of the treatments were not significantly different. ${ }^{62}$

The renoprotective effect of irbesartan has been tested in a study by Rossing et al. In this study, 52 hypertensive patients with type 2 diabetes and microalbuminuria already on antihypertensive treatment were included. After a twomonth wash-out of other drugs, patients were randomized to receive irbesartan 300, 600, and $900 \mathrm{mg}$ once daily. After a 10-week treatment period, ultrahigh doses of irbesartan were well tolerated and provided additional renoprotection independent of changes in BP values and glomerular filtration rate, compared with irbesartan $300 \mathrm{mg}$. ${ }^{63}$

Administration of irbesartan twice daily has been evaluated in a study by Polónia et al who investigated whether blockage of angiotensin II receptors by irbesartan could reverse the nondipper circadian rhythm of BP to a dipper pattern in 12 black salt-sensitive hypertensive patients on a high sodium diet (300 mmol per day) after a two-week placebo administration, followed by two weeks on irbesar$\tan 150 \mathrm{mg} /$ day, two weeks on placebo, and two weeks on irbesartan $300 \mathrm{mg} /$ day. On the last day of placebo, and of the irbesartan $150 \mathrm{mg} /$ day and irbesartan $300 \mathrm{mg}$ /day treatments, 24-hour BP and urinary 24-hour excretion of sodium and potassium were measured. Compared with placebo, irbesartan significantly increased serum potassium and plasma renin activity and reduced fractional excretion of potassium and plasma aldosterone levels in a dose-dependent manner, without significant changes in body weight. The authors concluded that irbesartan can reverse the nondipper BP profile in salt-sensitive hypertensive patients on a high-salt diet, restoring the nocturnal BP decline by a predominantly dosedependent reduction of night time BP. This result occurred independently of increased natriuresis. Evidence has been accumulating to suggest that ambulatory BP values are more strongly correlated with markers of cardiovascular disease than are clinic BP values. ${ }^{64}$

The main studies that showed a significant effect of irbesartan in reducing microalbuminuria and decreasing the risk of diabetic nephropathy were Irbesartan Microalbuminuria type 2 Diabetes in Hypertensive Patients (IRMA II) ${ }^{65}$ and Irbesartan in Diabetic Nephropathy Trial (IDNT). ${ }^{66}$ These are two long-term (2-3 year) trials showing that the irbesartan is effective in reducing the progression of renal disease in patients with type 2 diabetes and high BP. In each trial, the standard of care for diabetes mellitus was maintained. Using conventional antihypertensive therapy, including diuretics, beta-blockers, and CCBs (but not ACEIs or other ARBs), $\mathrm{BP}$ control was similar in the placebo- and ARB-treated groups.

The IRMA II study (Table 1) evaluated the renoprotective effect of irbesartan, in hypertensive patients with type 2 diabetes and microalbuminuria. ${ }^{65}$ This multinational, randomized, double-blind, placebo-controlled study enrolled a total 
Table I The Irbesartan Microalbuminuria type 2 Diabetes in Hypertensive Patients II study

\begin{tabular}{|c|c|}
\hline Title & $\begin{array}{l}\text { IRMA II (The Irbesartan MicroAlbuminuria type } \mathbf{2} \\
\text { Diabetes in Hypertensive Patients Study) }\end{array}$ \\
\hline Study & Randomized, multicenter, placebo-controlled study \\
\hline Design & $\begin{array}{l}\text { Three parallel groups of patients receiving } \\
\text { irbesartan } 150 \mathrm{mg} / \text { day, } 300 \mathrm{mg} / \text { day, or placebo }\end{array}$ \\
\hline Target BP & $<135 / 85 \mathrm{mmHg}$ after three months \\
\hline Patients (n) & 590 \\
\hline $\begin{array}{l}\text { Patient } \\
\text { characteristics }\end{array}$ & $\begin{array}{l}\text { Type } 2 \text { diabetes } \\
\text { Hypertension } \\
\text { Microalbuminuria }\end{array}$ \\
\hline Primary endpoint & $\begin{array}{l}\text { Onset of diabetic nephropathy in patients } \\
\text { with type } 2 \text { diabetes } \\
\text { Definition of diabetic nephropathy: } \\
\text { urinary albumin excretion rate in an overnight } \\
\text { specimen }>200 \mu g / \text { min and } 30 \% \text { of the baseline } \\
\text { rate on at least two consecutive visits }\end{array}$ \\
\hline $\begin{array}{l}\text { Secondary } \\
\text { endpoints }\end{array}$ & $\begin{array}{l}\text { Changes in level of albuminuria } \\
\text { Changes in creatinine clearance } \\
\text { Restoration of normoalbuminuria } \\
\text { Urinary albumin excretion rate in an overnight } \\
\text { specimen } 20 \mu \mathrm{g} / \mathrm{min}\end{array}$ \\
\hline $\begin{array}{l}\text { Median follow-up } \\
\text { treatment }\end{array}$ & 2.0 years \\
\hline Treatment & Irbesartan 150 mg/day (195 patients) \\
\hline dosages & $\begin{array}{l}\text { Irbesartan } 300 \text { mg/day (194 patients) } \\
\text { Placebo (20I patients) }\end{array}$ \\
\hline $\begin{array}{l}\text { Results } \\
\text { (primary } \\
\text { endpoint) }\end{array}$ & $\begin{array}{l}\text { Nephropathy prevalence } \\
14.9 \% \text { placebo group } \\
7.9 \% \text { irbesartan } 150 \mathrm{mg} / \text { day }^{\mathrm{a}} \\
5.2 \% \text { irbesartan } 300 \mathrm{mg} / \text { day }^{\mathrm{b}, \mathrm{c}} \\
\text { Irbesartan } 300 \mathrm{mg} / \text { day reduced the progression } \\
\text { of diabetic nephropathy by } 70 \% \text {. }\end{array}$ \\
\hline $\begin{array}{l}\text { Results } \\
\text { (secondary } \\
\text { endpoints) }\end{array}$ & $\begin{array}{l}\text { Urinary albumin excretion rate significantly } \\
\text { decreased with irbesartan versus placebo }(-38 \% \\
\text { in the irbesartan group })^{\mathrm{d}} \\
\text { Decline in creatinine clearance did not significantly } \\
\text { differ between groups } \\
\text { Average blood pressure } \\
-144 / 83 \mathrm{mmHg} \text { placebo } \\
-143 / 83 \mathrm{mmHg} \text { irbesartan } 150 \mathrm{mg} / \text { day } \\
-141 / 83 \mathrm{mmHg} \text { irbesartan } 300 \mathrm{mg} / \text { day }^{\mathrm{e}}\end{array}$ \\
\hline Conclusions & $\begin{array}{l}\text { Significant reduction of progression from } \\
\text { microalbuminuria to nephropathy in diabetic } \\
\text { patients treated with irbesartan, independently } \\
\text { of BP control } \\
\text { renoprotection independent of blood pressure } \\
\text { reduction }\end{array}$ \\
\hline
\end{tabular}

a $P=0.08 ;$ b $P<0.001 ; c p<0.001$ for comparison between placebo and irbesartan $300 \mathrm{mg} /$ day; ${ }^{d} P<0.00 \mathrm{I}$ for irbesartan compared with placebo; ${ }^{e} P=0.004$ for the comparison of systolic blood pressure between the combined irbesartan groups and the placebo group.

of 590 hypertensive patients with type 2 diabetes and persistent microalbuminuria who received irbesartan at a dose of either $150 \mathrm{mg}$ daily or $300 \mathrm{mg}$ daily, or placebo. The primary efficacy measure was the time from the baseline visit to the first detection of overt nephropathy, defined by a urinary albu- min excretion rate in an overnight specimen $>200 \mu \mathrm{g} / \mathrm{min}$ and at least $30 \%$ higher than the baseline rate on at least two consecutive visits. At the end of the study, nephropathy developed in 30 patients in the placebo group, compared with 19 patients in the $150 \mathrm{mg}$ irbesartan group and 10 patients in the $300 \mathrm{mg}$ irbesartan group. The unadjusted hazard ratio (HR) for diabetic nephropathy was $0.61(P=0.08)$ in the $150 \mathrm{mg}$ group and $0.30(P<0.001)$ in the $300 \mathrm{mg}$ group. The average BP during the course of the entire study was $144 / 83 \mathrm{mmHg}$ in the placebo group, $143 / 83 \mathrm{mmHg}$ in the $150 \mathrm{mg}$ irbesartan group, and $141 / 83 \mathrm{mmHg}$ in the $300 \mathrm{mg}$ irbesartan group ( $P=0.004$ for the comparison of SBP between the placebo group and the combined irbesartan groups).

After adjustment for BP achieved during the study and the baseline level of microalbuminuria, the HR for diabetic nephropathy was 0.56 in the $150 \mathrm{mg}$ group $(P=0.05)$ and 0.32 in the $300 \mathrm{mg}$ group $(P<0.001)$. Serious adverse events were less frequent among the patients treated with irbesartan $(P=0.02)$. Irbesartan reduced the level of urinary albumin excretion throughout the study. In the irbesartan $150 \mathrm{mg}$ group, urinary albumin excretion decreased by $24 \%$ and, in the $300 \mathrm{mg}$ group, decreased by $38 \%$, whereas the placebo group had a $2 \%$ decrease $(P<0.001$ for the comparison between placebo and combined irbesartan groups). There was a significantly smaller reduction in the level of albuminuria in the $150 \mathrm{mg}$ group than in the $300 \mathrm{mg}$ group $(P<0.001)$.

During this 24-month study, overt nephropathy developed in 30 patients in the placebo group, compared with 19 patients in the $150 \mathrm{mg}$ group $(P=0.08)$ and 10 patients in the $300 \mathrm{mg}$ group $(P<0.001)$. The unadjusted HR for diabetic nephropathy was $0.61(P=0.08)$ in the $150 \mathrm{mg}$ group and 0.30 $(P<0.001)$ in the $300 \mathrm{mg}$ group. After adjustment for the baseline level of microalbuminuria and the BP achieved during the study, the HR for diabetic nephropathy was 0.56 in the $150 \mathrm{mg}$ group $(P=0.05)$ and 0.32 in the $300 \mathrm{mg}$ group $(P<0.001)$. At the three-month visit, the decrease in creatinine clearance for the placebo group and the $300 \mathrm{mg}$ irbesartan group separated and continued to diverge. The decline in creatinine clearance during the initial three-month period was greater than the sustained decline from three months to 24 months. The initial declines were $0.9,1.0$, and 1.9 in the placebo, and irbesartan $150 \mathrm{mg}$ and $300 \mathrm{mg}$ groups, respectively, compared with declines of $0.1,0.2$, and 0.2 between months 3 and 24. Neither the initial decline nor the sustained decline differed significantly among the three groups. Irbesartan reduced the level of urinary albumin excretion throughout the study. Urinary albumin decreased by $24 \%$ in the $150 \mathrm{mg}$ group, $38 \%$ in the $300 \mathrm{mg}$ group, and $2 \%$ in the placebo 
group ( $P<0.001$ for the comparison between placebo and the combined irbesartan groups). There was a significantly smaller reduction in the level of albuminuria in the $150 \mathrm{mg}$ group than in the $300 \mathrm{mg}$ group $(P<0.001)$.

In the other relevant large study, the IDNT ${ }^{66}$ compared the renoprotective effect of irbesartan and amlodipine in patients with type 2 diabetes and microalbuminuria (Table 2), beyond the effect of these two drugs on BP reduction. It was a prospective, randomized, double-blind, placebo-controlled study including 1175 patients from 210 clinical centers. Patients enrolled in this study had hypertension and nephropathy due to type 2 diabetes. Patients were randomized to receive irbesartan $300 \mathrm{mg} /$ day, amlodipine $10 \mathrm{mg}$ /day, or placebo. Groups were compared according to time to the primary composite endpoint of a doubling of baseline serum creati-

\section{Table 2 The IDNT study}

\begin{tabular}{|c|c|}
\hline Title & IDNT (Irbesartan Diabetic Nephropathy Trial) \\
\hline Study & $\begin{array}{l}\text { Prospective randomized, multicenter, double- } \\
\text { blind placebo-controlled study }\end{array}$ \\
\hline Design & $\begin{array}{l}\text { Groups were compared with regard to the time } \\
\text { to the primary composite endpoint }\end{array}$ \\
\hline Target BP & $135 / 85 \mathrm{mmHg}$ or less in all groups \\
\hline Patients (n) & 1.715 \\
\hline Patient & Type 2 diabetes \\
\hline characteristics & Nephropathy due to type 2 diabetes \\
\hline Primary endpoint & $\begin{array}{l}\text { Comparison between irbesartan and amlodipine } \\
\text { efficacy in protection against the progression of } \\
\text { nephropathy due to type } 2 \text { diabetes, } \\
\text { independently of BP reduction }\end{array}$ \\
\hline Secondary endpoints & $\begin{array}{l}\text { Overall mortality in the two treatment groups } \\
\text { Rates of cardiovascular events in the two } \\
\text { treatment groups }\end{array}$ \\
\hline Treatments & $\begin{array}{l}\text { Irbesartan } 300 \mathrm{mg} / \text { day } \\
\text { Amlodipine } 10 \mathrm{mg} / \text { day }\end{array}$ \\
\hline $\begin{array}{l}\text { Results } \\
\text { (primary endpoint) }\end{array}$ & $\begin{array}{l}\text { Irbesartan reduction of composite primary end- } \\
\text { point } 20 \% \text { lower versus placebo and } 23 \% \text { versus } \\
\text { amlodipine } \\
\text { Relative risk of doubling of serum creatinine } \\
\text { concentration } 33 \% \text { lower with irbesartan versus } \\
\text { placebo and } 37 \% \text { versus amlodipine } e^{c, d} \\
\text { Relative risk of end-stage renal disease was } 23 \% \\
\text { lower in irbesartan group than in both other } \\
\text { groups }^{\mathrm{e}}\end{array}$ \\
\hline $\begin{array}{l}\text { Results (secondary } \\
\text { endpoints) }\end{array}$ & $\begin{array}{l}\text { No significant differences in the rate of death } \\
\text { from any cause and in the cardiovascular } \\
\text { composite endpoint }\end{array}$ \\
\hline Conclusions & $\begin{array}{l}\text { Significant reduction of progression from } \\
\text { microalbuminuria to nephropathy in diabetic } \\
\text { patients treated with irbesartan } \\
\text { Renoprotection independent of blood pressure } \\
\text { reduction }\end{array}$ \\
\hline
\end{tabular}

a $P=0.02$ for irbesartan versus placebo; $b P=0.006$ for irbesartan vs amlodipine; $c P=$ 0.003 for irbesartan versus placebo; ${ }^{\mathrm{d} P}<0.00 \mathrm{I}$ for irbesartan versus amlodipine; eP $=0.07$ for both comparisons. nine concentration, development of end-stage renal disease, and death from any cause. The mean follow-up duration was 2.6 years. At the end of the study, treatment with irbesartan was associated with a $20 \%$ and $23 \%$ reduction in risk of the primary composite endpoint compared with placebo and amlodipine, respectively $(P=0.006)$. The relative risk of doubling of the serum creatinine concentration was $33 \%$ and $37 \%$ lower in the irbesartan group compared with the placebo and amlodipine groups $(P=0.003$ and $P<0.001$, respectively). Treatment with irbesartan was associated with a significantly lower risk of end-stage renal disease $(-23 \%)$ compared with that observed in the other groups $(P=0.07$ for both comparisons). These results were not affected by reduction in $\mathrm{BP}$ values. The increase in serum creatinine levels was slower in the irbesartan group compared with the placebo $(-24 \%)$ and amlodipine $(21 \%)$ groups $(P=0.008$ and $P=0.002$, respectively). No significant differences between groups were observed in the rate of death from any cause or in the cardiovascular composite endpoint.

Although the IRMA II and IDNT studies provided strong support for the beneficial effect of irbesartan in renoprotection, both studies included patients with hypertension who had been previously treated with antihypertensive drugs. In a short-term study, irbesartan was administered to newly diagnosed drug-naive patients; the effects of irbesartan $150 \mathrm{mg}$ bid on microalbuminuria were observed in normotensive type 2 diabetic patients, suggesting that the renoprotective action of irbesartan is probably due to a direct action on renal hemodynamics and glomerular morphology. ${ }^{67}$

More recently, studies have demonstrated a precise role for irbesartan and statins in regulation of vascular dysfunction. In the Endothelial Protection, AT, Blockade and Cholesterol-Dependent Oxidative Stress (EPAS) trial, the investigators showed that statin and $\mathrm{AT}_{1}$ blocker therapy independently and in combination improved both the antiatherosclerotic endothelial expression quotient and endothelial function. In this study, 60 patients with stable coronary artery disease undergoing elective coronary artery bypass grafting surgery were randomized four weeks before surgery to no ARBs and/or statins (controls), pravastatin $40 \mathrm{mg} /$ day, irbesartan $150 \mathrm{mg} /$ day, or pravastatin in combination with irbesartan at the same dosages. The primary endpoint was a priori therapy-dependent regulation of the antiatherosclerotic endothelial expression calculated marker of endothelial regulation. At the end of the study, association of irbesartan and pravastatin significantly improved endothelial expression of antiatherosclerotic and proatherothrombotic genes and endothelial function in arteries in these patients with coro- 
nary artery disease. Moreover, preoperative therapy with irbesartan and pravastatin and their combination improved endothelial function in internal mammary artery rings. ${ }^{68}$

Recently, many studies have focussed on molecular markers of the inflammatory mechanisms involved in atherogenesis, and particular attention has been given to inflammatory molecules which interact with the endothelium, such as tumor necrosis factor- $\alpha$, vascular cell adhesion molecule, and superoxides. In a study by Navalkar et al, irbesartan significantly improved levels of inflammatory molecules in 33 normotensive patients with coronary artery disease, and the maximal suppression of inflammatory markers was observed after 12 weeks. ${ }^{69}$ In another study, treatment with irbesartan was effective in reducing the pro-oxidative environment seen in patients with coronary artery disease. Lag time for LDL oxidation increased $32 \%$ at 12 weeks, suggesting that increased resistance of LDL modification during serum and lipid peroxidation decreased by $36 \%$ with irbesartan compared with placebo. In addition, superoxide levels and monocyte-binding capacity were also significantly reduced in coronary artery disease patients receiving irbesartan. ${ }^{70}$

\section{Conclusions}

Irbesartan is an angiotensin II receptor type 1 antagonist which has demonstrated significant efficacy in reducing BP in patients with high cardiovascular risk. In comparative trials, irbesartan seems significantly more effective than other ARBs in the treatment of mild to moderate essential hypertension, and is as effective as enalapril or atenolol. Many studies also show an additive antihypertensive effect when hydrochlorothiazide is added to irbesartan monotherapy. In hypertensive patients, the presence of an abnormal circadian BP rhythm as a result of lack of nocturnal BP decrease (nondippers) has been reported to be associated with a higher risk of cardiovascular end organ damage and a poorer prognosis for cardiovascular events compared with dippers (who show a normal nocturnal BP decrease). Irbesartan is able to modulate circadian BP rhythms and thereby significantly modifies the risk of organ damage due to hypertension and endothelial dysfunction, such as increased intima media thickness and left ventricular hypertrophy. Irbesartan also induces statistically significant regression of left ventricular mass in patients with hypertension and left ventricular hypertrophy, and preliminary evidence suggests it has beneficial hemodynamic effects in patients with heart failure.

Moreover, irbesartan counteracts a number of other defects that lead to high cardiovascular risk, in particular insulin resistance and endothelial dysfunction. The so-called ancillary effects of irbesartan, which are partially shared by other ARBs, have been highlighted in recent studies. Particular interest has arisen about the effects of irbesartan on vascular dysfunction, which represents one of the major mechanisms that lead to atherosclerosis, and metabolic and cardiovascular diseases. A beneficial effect of irbesartan on glomerular filtration and microalbuminuria has been established in large clinical trials, such as IDNT and IRMA II. Many data suggest a relationship between BP and endothelial dysfunction, so the role of irbesartan in modulation of vasodilatation and cytokines disorders could be explained in further experimental and clinical studies. Furthermore, the connection between insulin resistance, hypertension, and endothelial dysfunction, as well as the effects of ARBs on these mechanisms, has not been yet completely explained. In conclusion irbesartan is useful for clinicians for treatment of hypertension and prevention of organ damage, and appears well tolerated also at high dosage.

\section{Disclosures}

The authors report no conflict of interest in this work.

\section{References}

1. Kannel WB, Gordon T, Schwartz MJ. Systolic versus diastolic blood pressure and risk of coronary heart disease. The Framingham study. $\mathrm{Am}$ J Cardiol. 1971;27:335-346.

2. MacMahon S, Peto R, Cutler J, et al. Blood pressure, stroke and coronary heart disease. Part 1. Prolonged differences in blood pressure: Prospective observational studies corrected for the regression dilution bias. Lancet. 1990;335:765-774.

3. Stamler J, Stamler R, Neaton JD. Blood pressure, systolic and diastolic, and cardiovascular risks. US population data. Arch Intern Med. 1993;153:598-615.

4. Staessen JA, Gasowski J, Wang JG, et al. Risks of untreated and treated isolated systolic hypertension in the elderly: Meta-analysis of outcome trials. Lancet. 2000;355:865-872.

5. Lewington S, Clarke R, Qizilbash N, Peto R, Collins R; for the Prospective Studies Collaboration. Age-specific relevance of usual blood pressure to vascular mortality: A meta-analysis of individual data for one million adults in 61 prospective studies. Lancet. 2002:14;360:1903-1913.

6. Chobanian AV, Bakris GL, Black HR, et al. The Seventh Report of the Joint National Committee on Prevention, Detection, Evaluation, and Treatment of High Blood Pressure: The JNC 7 report. JAMA. 2003;289:2560-2572.

7. Whitworth JA, Chalmers J. World Health Organization - International Society of Hypertension (WHO/ISH) hypertension guidelines. Clin Exp Hypertens. 2004;26:747-752.

8. 2007 ESH-ESC Practice Guidelines for the Management of Arterial Hypertension: ESH-ESC Task Force on the Management of Arterial Hypertension. J Hypertens. 2007;25:1751-1762.

9. Mancia G, De Backer G, Dominiczak A, et al. ESH-ESC Task Force on the Management of Arterial Hypertension. J Hypertens. 2007;25(9):1751-1762.

10. Kannel WB, Gordon T, Schwartz MJ. Systolic versus diastolic blood pressure and risk of coronary heart disease. The Framingham study. Am J Cardiol. 1971;27:335-346. 
11. Lawes CM, Bennett DA, Lewington S, Rodgers A. Blood pressure and coronary heart disease: A review of the evidence. Semin Vasc Med. 2002;2:355-368.

12. Stamler J, Stamler R, Neaton JD. Blood pressure, systolic and diastolic, and cardiovascular risks. US population data. Arch Intern Med. 1993;153:598-615.

13. Benetos A, Thomas F, Bean K, Gautier S, Smulyan H, Guize L. Prognostic value of systolic and diastolic blood pressure in treated hypertensive men: Clarification. Arch Intern Med. 2003;163:121.

14. White WB. Cardiovascular risk and therapeutic intervention for the early morning surge in blood pressure and heart rate. Blood Press Monit. 2001;6:63-72.

15. Mancia G, Ferrari A, Gregorini L, et al. Blood pressure and heart rate variabilities in normotensive and hypertensive human beings. Circ Res. 1983;53:96-104.

16. Palatini P, Penzo M, Racioppa A, et al. Clinical relevance of nighttime blood pressure and of daytime blood pressure variability. Arch Intern Med. 1992;152:1855-1860.

17. Sander D, Klingelhofer J. Diurnal systolic blood pressure variability is the strongest predictor of early carotid atherosclerosis. Neurology. 1996;47:500-507.

18. Sander D, Klingelhofer J. Early carotid atherosclerosis of the internal and external carotid artery related to twenty-four-hour blood pressure variability. Cerebrovasc Dis. 1997; 7:338-344

19. Luscher TS, Vanhoutte PM. The endothelium: Modulator of cardiovascular function. Boca Raton, FL: CRC Press; 1990.

20. Ross R. The pathogenesis of atherosclerosis: A perspective for the 1990s. Nature. 1993;362:801-809.

21. Mattei P, Virdis A, Ghiadoni L, Taddei S, Salvetti A. Endothelial function in hypertension. J Nephrol. 1997;10:192-197.

22. Taddei S, Virdis A, Ghiadoni L, Sudano I, Salvetti A. Effects of antihypertensive drugs on endothelial dysfunction: Clinical implications. Drugs. 2002;62:265-284.

23. Taddei S, Virdis A, Ghiadoni L, Magagna A, Salvetti A. Vitamin $\mathrm{C}$ improves endothelium-dependent vasodilation by restoring nitric oxide activity in essential hypertension. Circulation. 1998;97:2222-2229.

24. Cai H, Harrison DG. Endothelial dysfunction in cardiovascular diseases: The role of oxidant stress. Circ Res. 2000;87:840-844.

25. Stankevicius E, Martinez AC, Mulvany MJ, Simonsen U. Blunted acetylcholine relaxation and nitric oxide release in arteries from renal hypertensive rats. J Hypertens. 2002;20:1571-1579.

26. Vallance P, Coller J, Moncada S. Effects of endothelium-derived nitric, 22 oxide on peripheral arteriolar tone in man. Lancet. 1989;2:997-1000.

27. Vita JA, Treasure CB, Nabel EG, et al. Coronary vasomotor response to acetylcholine relates to risk factors for coronary artery disease. Circulation. 1990;81:491-497.

28. Kuga T, Egashira K, Mohri M, et al. Bradykinin-induced vasodilation is impaired at the atherosclerotic site but is preserved at the spastic site of human coronary arteries in vivo. Circulation. 1995;92:183-189.

29. Linder L, Kiowski W, Buhler FR, Luscher TF. Indirect evidence for the release of endothelium-derived relaxing factor in the human forearm circulation in vivo: Blunted response in essential hypertension. Circulation. 1990;81:1762-1767.

30. Panza JA, Quyyumi AA, Brush JE Jr, Epstein SE. Abnormal endothelium dependent vascular relaxation in patients with essential hypertension. N Engl J Med. 1990;323:22-27.

31. Taddei S, Virdis A, Mattei P, Salvetti A. Vasodilation to acetylcholine in primary and secondary forms of human hypertension. Hypertension. 1993;21:929-933.

32. Panza JA, Garcma CE, Kilcoyne CM, Quyyumi A, Cannon RO III. Impaired endothelium-dependent vasodilation in patients with essential hypertension: Evidence that nitric oxide abnormality is not localized to a single signal transduction pathway. Circulation. 1995;91:1732-1738.
33. Bautista LE. Inflammation, endothelial dysfunction, and the risk of high blood pressure: Epidemiologic and biological evidence. J Hum Hypertens. 2003;17, 223-230.

34. Ceriello A, Assaloni R, Da Ros R, et al. Effect of atorvastatin and irbesartan, alone and in combination, on postprandial endothelial dysfunction, oxidative stress, and inflammation in type 2 diabetic patients. Circulation. 2005;111:2518-2524.

35. Ghiadoni L, Magagna A, Versari D, et al. Different effect of antihypertensive drugs on conduit artery endothelial function. Hypertension. 2003;41:1281-1286.

36. Cetinkalp SS, Karadeniz MM, Erdogan MA, Ozgen GA, Yilmaz CO. Short-term effects of irbesartan treatment on microalbuminuria in patients with normotensive type 2 diabetes. Saudi Med J. 2008;29:1414-1418.

37. Weekers L, Krzesinski JM. Clinical study of the month. Nephroprotective role of angiotensin II receptor antagonists in type 2 diabetes: Results of the IDNT and RENAAL trials Rev Med Liege. 2001;56:723-726.

38. Bramlage P, Durand-Zaleski I, Desai N, Pirk O, Hacker C. The value of irbesartan in the management of hypertension. Expert Opin Pharmacother. 2009;10:1817-1831.

39. von zur Mühlen B, Kahan T, Hägg A, Millgård J, Lind L. Treatment with irbesartan or atenolol improves endothelial function in essential hypertension. J Hypertens. 2001;19:1813-1818.

40. Schäfer A, Fraccarollo D, Tas P, Schmidt I, Ertl G, Bauersachs J. Endothelial dysfunction in congestive heart failure: ACE inhibition vs angiotensin II antagonism. Eur J Heart Fail. 2004;6:151-159.

41. Vachharajani NN, Shyu WC, Chando TJ, Everett DW, Greene DS, Barbhaiya RH. Oral bioavailability and disposition characteristics of irbesartan, an angiotensin antagonist, in man. J Clin Pharmacol. 1998;38:702-707.

42. Ritschel WA. Gerontokinetics. Caldwell, NJ: Telford Press; 1988.

43. Sica DA, Marino MR, Hammett JL, Ferreira I, Ford NF. Pharmacokinetics of irbesartan are not altered by renal impairment or hemodialysis. Clin Pharmacol Ther. 1997;62:902-909.

44. Vachharajani NN, ShyuWC, Mantha S, ParkJS, Greene DS, Barbhaiya RH. Lack of effect of food on the oral bioavailability of irbesartan in healthy male volunteers. J Clin Pharmacol. 1998;38:433-436.

45. Vachharajani N, Shyu WC, Smith RA, Douglas S, Greene DS. The effects of age and gender on the pharmacokinetics of irbesartan. J Clin Pharmacol. 1998;46:611-613.

46. Cazaubon C, Gougat J, Bousquet F, et al. Pharmacological characterization of SR 47436, a new nonpeptide AT1 subtype angiotensin II receptor antagonist. J Pharmacol Exp Ther. 1993;265:826-834.

47. O’Donnell MP, Crary GS, Oda H, Kasiske BL, Powell JR, Keane WF. Irbesartan lowers blood pressure and ameliorates renal injury in experimental non-insulin-dependent diabetes mellitus. Kidney Int Suppl. 1997;63:S218-S220.

48. Fogari R, Ambrosoli S, Corradi L, et al. 24-Hour blood pressure control by once daily irbesartan as assessed by ambulatory blood pressure monitoring. J Hypertens. 1997;15:1511-1518.

49. Mugellini A, Preti P, Zoppi A, et al. Effect of delapril-manidipine combination vs irbesartan-hydrochlorothiazide combination on fibrinolytic function in hypertensive patients with type II diabetes mellitus. J Hum Hypertens. 2004;18:687-691.

50. Schmieder RE, Schwertfeger M, Bramlage P. Significance of initial blood pressure and comorbidity for the efficacy of a fixed combination of an angiotensin receptor blocker and hydrochlorothiazide in clinical practice. Vasc Health Risk Manag. 2009;5:991-1000.

51. Bobrie G, Delonca J, Moulin C, Giacomino A, Postel-Vinay N, Asmar R. Comparative Study of Efficacy of Irbesartan/HCTZ with Valsartan/ HCTZ Using Home Blood Pressure Monitoring in the TreAtment of Mild-to-Moderate Hypertension (COSIMA) Investigators. Am J Hypertens. 2005;18:1482-1488.

52. Bramlage P. Fixed combination of irbesartan and hydrochlorothiazide in the management of hypertension. Vasc Health Risk Manag. 2009;5: $213-224$. 
53. Derosa G, Cicero AF, Gaddi A, Mugellini A, Ciccarelli L, Fogari R. Effects of doxazosin and irbesartan on blood pressure and metabolic control in patients with type 2 diabetes and hypertension. J Cardiovasc Pharmacol. 2005;45:599-604.

54. Neutel JM, Germino FW, Smith D. Comparison of monotherapy with irbesartan $150 \mathrm{mg}$ or amlodipine $5 \mathrm{mg}$ for treatment of mild-to-moderate hypertension. J Renin Angiotensin Aldosterone Syst. 2005;6:84-89.

55. Fogari R, Zoppi A, Mugellini A, et al. Efficacy and safety of two treatment combinations of hypertension in very elderly patients. Arch Gerontol Geriatr. 2009;48:401-405.

56. Larochelle P, Flack JM, Marbury TC, Sareli P, Krieger EM, Reeves RA. Effects and tolerability of irbesartan versus enalapril in patients with severe hypertension. Irbesartan Multicenter Investigators. Am J Cardiol. 1997;80:1613-1615.

57. Coca A, Calvo C, García-Puig J, et al. A multicenter, randomized, double-blind comparison of the efficacy and safety of irbesartan and enalapril in adults with mild to moderate essential hypertension, as assessed by ambulatory blood pressure monitoring: The MAPAVEL Study. Clin Ther. 2002;24:126-138.

58. Mancia G, Korlipara K, van Rossum P, Villa G, Silvert B. An ambulatory blood pressure monitoring study of the comparative antihypertensive efficacy of two angiotensin II receptor antagonists, irbesartan and valsartan. Blood Press Monit. 2002;7:135-142.

59. Brosnan MJ, Hamilton CA, Graham D, Lygate CA, Jardine E, Dominiczak AF. Irbesartan lowers superoxide levels and increases nitric oxide bioavailability in blood vessels from spontaneously hypertensive stroke-prone rats. J Hypertens. 2002;20:281-286.

60. Wilmink HW, Banga JD, Hijmering M, Erkelens WD, Stroes ES, Rabelink TJ. Effect of angiotensin-converting enzyme inhibition and angiotensin II type 1 receptor antagonism on postprandial endothelial function. J Am Coll Cardiol. 1999;34:140-145.

61. Ceriello A, Assaloni R, Da Ros R, et al. Effect of atorvastatin and irbesartan, alone and in combination, on postprandial endothelial dysfunction, oxidative stress, and inflammation in type 2 diabetic patients. Circulation. 2005;111:2518-2524.
62. Kassler-Taub K, Littlejohn T, Elliott W, et al; for the Irbesartan/Losartan Study Investigators. Comparative efficacy of two angiotensin II receptor antagonists, irbesartan and losartan, in mild-to-moderate hypertension. Am J Hypertension. 1998;11:445-453.

63. Rossing K, Schjoedt K, Jensen BR, Boomsma F, Parving H-H. Enhanced renoprotective effects of ultrahigh doses of irbesartan in patients with type 2 diabetes and microalbuminuria. Kidney Int. 2005; 68:1190-1198.

64. Polónia J, Diogo D, Caupers P, Damasceno A. Influence of two doses of irbesartan on non-dipper circadian blood pressure rhythm in salt-sensitive black hypertensives under high salt diet. J Cardiovasc Pharmacol. 2003;42:98-104.

65. Parving HH, Lehnert H, Brochner-Mortensen J, Gomis R, Steen Andersen S, Arner P, for the Irbesartan in Patients with type 2 Diabetes and Microalbuminuria Study Group. The effect of irbesartan on the development of diabetic nephropathy in patients with type 2 diabetes. N Engl J Med. 2001;345:870-878.

66. Lewis EJ, Hunsicker LG, Clarke WR, et al. Renoprotective effect of the angiotensin-receptor antagonist irbesartan in patients with nephropathy due to type 2 diabetes. $N$ Engl J Med. 2001;345:851-860.

67. Sasso FC, Carbonara O, Persico M, et al. Irbesartan reduces the albumin excretion rate in microalbuminuric type 2 diabetic patients independently of hypertension. Diabetes Care. 2002;25:1909-1913.

68. Morawietz H, Erbs S, Holtz J, et al. Endothelial protection, AT1 blockade and cholesterol-dependent oxidative stress: The EPAS trial. Circulation. 2006;114(1 Supp1):I296-I301.

69. Navalkar S, Parthasarathy S, Santanam N, Khan BV. Irbesartan, an angiotensin type 1 receptor inhibitor, regulates markers of inflammation in patients with premature atherosclerosis. J Am Coll Cardiol. 2001;37:440-444.

70. Khan BV, Navalkar S, Khan QA, Rahman ST, Parthasarathy S. Irbesartan, an angiotensin type 1 receptor inhibitor, regulates the vascular oxidative state in patients with coronary artery disease. $\mathrm{J}$ Am Coll Cardiol. 2001;38:1662-1667.
Integrated Blood Pressure Control

\section{Publish your work in this journal}

Integrated Blood Pressure Control is an international, peer-reviewed open-access journal focusing on the integrated approach to managing hypertension and risk reduction. Treating the patient and comorbidities together with diet and lifestyle modification and optimizing healthcare resources through a multidisciplinary team approach constitute key

\section{Dovepress}

features of the journal. This journal is indexed on American Chemical Society's Chemical Abstracts Service (CAS). The manuscript management system is completely online and includes a very quick and fair peerreview system, which is all easy to use. Visit http://www.dovepress.com/ testimonials.php to read real quotes from published authors. 